\title{
Accidental Poisoning in Young Children: an Emergency Medicine Perspective for Pakistan and Other Low-and Middle-Income Countries and a Call for Action
}

\author{
Huma Baqir ${ }^{1}$, Muhammad Akbar Baig ${ }^{2}$, Nick Brown ${ }^{4}$, Asad lqbal Mian ${ }^{3}$ \\ ${ }^{1}$ Aga Khan University Hospital, Karachi, Pakistan \\ 2Department of Emergency Medicine, Aga Khan University Hospital, Karachi, Pakistan \\ ${ }^{3}$ Departments of Emergency Medicine and Pediatrics and Child Health, Aga Khan University Hospital, Karachi, Pakistan \\ ${ }^{4}$ Salisbury District Hospital, Wiltshire, UK
}

Cite this article as: Baqir H, Baig MA, Brown N, Mian Al. Accidental Poisoning in Young Children: an Emergency Medicine Perspective for Pakistan and Other Low-and Middle-Income Countries and a Call for Action. Eurasian J Emerg Med 2017; 16: 140-3.

\begin{abstract}
Accidental pediatric poisoning (APP) is an important public health issue in both the developed and developing parts of the world. It continues to affect a number of children, but in Pakistan and other low- and middle-income countries (LMICs), few measures have been taken to counter it. As many of these children present to the Emergency Department (ED), the aim of our review was to analyze the biomedical literature regarding childhood-related accidental poisoning in general and in Pakistan and similar countries, in particular, with an emphasis on their emergency departments. We focused on children aged 0-5 years. This attempt was intended to be a first step toward gaining a better grasp of the epidemiology, following which we wish to suggest a simple management strategy. Additionally, we aim to identify the most common accidentally ingested agents in young children in Pakistan and assess the risk factors for poisoning and the efficacy of possible interventions. Given that accidental ingestions are entirely avoidable, we have focused on preventative steps and treatment. We thus present suggestions in this perspective piece for tackling the problem in resource-limited countries in general, where there is an urgent need for it.
\end{abstract}

Keywords: Accidental poisoning, childhood poisoning, low-middle income countries, emergency department, Pakistan

\section{Introduction}

By definition, poisoning is the injury or destruction of cells via inhalation, ingestion, injection, or absorption of a toxic substance. The prognostic key factors include the nature, dose, formulation and route of exposure of the poison, coexposure to other poisons, state of nutrition of the child, age, and pre-existing health conditions (1). In developing countries, poisoning has been recognized as a major health problem among children and adolescents (2).

Accidental poisoning is implicated in about $2 \%$ of all injury deaths in children in the developing nations (3). Current epidemiological studies regarding accidental poisoning in children have demonstrated a consistent pattern regarding the age and gen- der, being predominant in male children aged less than 6 years, as they are considered to be more actively involved in exploring their environment (4). Evidently, as per a World Health Organization (WHO) report on child injury prevention, the rate of fatal poisoning is highest for children aged $<1$ year. Since fatal poisoning rates in low to middle-income countries (LMICs) are four times that of high-income countries (1), it becomes evident that acute poisoning is an important cause of morbidity and mortality in children, which can be significantly and effectively controlled by preventive and educational measures (5). Unfortunately, due to the lack of national database resources on pediatric poisoning and relevant legal or government-run institutions to facilitate the process, the exact scale of the problem in Pakistan is very difficult to ascertain. 
In this brief review, we aim to identify the epidemiology, risk factors, and interventions in the face of accidental pediatric poisoning (APP). Additionally, we wished to focus on the gaps in knowledge as far as the situation in the LMICs was concerned. We also aimed to derive independent solutions to the problem and explore ways in which we could develop them further.

A thorough knowledge of the risk factors and their interactions may be useful in planning preventive measures against childhood poisoning. Studies have noted that APP typically occurs in the morning, when children are at home and at play (6). The risk particularly increased when cleaning products were stored in kitchenware, spray bottles, or food containers (7), with the age group of 1-3 years being most at risk (8).

The child's accidental exposure to toxic substances represents a complex interplay of host, agent, and environmental factors. Host factors associated with unintentional poisoning include young preschool age, male sex, and a curious, impulsive personality (9-11), with intentional poisoning being more common to adolescence and females (10). In addition, ingestion was found to be the major route of poisoning, according to the American Poison Control Centre (PCC) (12). Interestingly, of the various toxic ingestions included, kerosene oil was found to be the most commonly involved agent in the developing countries of South Asia and some parts of Africa $(4,13)$, followed by Organophosphorous compounds such as pesticides. This was particularly prevalent in countries, such as Pakistan, where there is a noticeable lack of safety measures involving manufacturers and caregivers alike. Other hazardous compounds used by young children out of inquisitiveness are pharmaceuticals, such as cough/cold preparations and sedatives/hypnotics (12).

The ease of access also increased the risk; when questioned, only $30 \%$ of caregivers claimed to appropriately store hazardous materials at home (6). Additionally, more than $50 \%$ of the parents incorrectly perceived antibiotics and oral contraceptives as harmful in small quantities and cough medications to be harmful only in large quantities. One in five parents was also unaware of the potential toxicity of iron tablets (15).

Since over-the-counter medications, such as analgesics are widely available at home, their accessibility makes them more likely to be associated with APP compared to prescription medications, which are falsely perceived as being more involved (15). Interestingly, although the child-resistant (CR) packaging claims to prevent poisoning, paracetamol - which usually enjoys a CR status internationally - is primarily involved in accidents. Crust formation around the cap, improper closure, and lack of customer counseling ${ }^{[15]}$ may explain the observation.

Although few studies have been conducted in Pakistan in this regard, a low socioeconomic status (48\%), storage of kerosene and petroleum in soft drink bottles (40\%), absence of mother's formal education (38\%), child hyperactivity (19\%), and unsafe storage $(12 \%)$ emerged as key role players in APPs within the country (16) an observation that can also possibly be applied to other LMICs.
Most cases of APP in Pakistan and its surroundings involved the misuse of household products $(47.0 \%)$, drugs (21.8\%), industrial chemicals (7.9\%), and agricultural pesticides (9.1\%) (16). In the United Kingdom, on the contrary, medications accounted for more than $50 \%$ of the bulk, and household products for around onethird (17).

In India, Sri Lanka, and Pakistan, specifically, the household products entailed pyrethroids, thermometer mercury, rodenticides, phenyl, detergents, and corrosives - with kerosene being the most common agent that poisoned overall. Likewise, the most common drugs involved included anticonvulsants, thyroid hormones, benzodiazepines, analgesics, oral contraceptives, phenothiazines, and iron-supplements (19).

Certain strategies can be undertaken to prevent accidental poisoning. For instance, placing substances in their usual storage place immediately after use, safely disposing unwanted medicines, using substances that contain bitterness-causing agents, and educating children about the dangers of poisoning have all proven to be helpful preventative measures (18). Relating incidents in a "story-telling" style - via parent networkers, the media, maternal and child nurses - has been identified as a way to spread awareness and consequently prevent unintentional pediatric poisoning (20). Other awareness campaigns should also be initiated to make parents aware of the hazards of accidental poisoning $(1,21)$.

It is believed that strategies dealing with only one substance may be more effective than a general poison-prevention approach (22). In addition, the provision of free locks, PCC number stickers, and syrup of ipecac (a natural emetic) have proven to be effective in keeping the incident under control (1). Legislation regarding CR packaging of medicines and household chemicals should also be formulated $(1,19)$. Another prevention strategy came in the form of poison-warning stickers, such as "Mr. Yuk," which were designed to discourage children from handling the containers or ingesting the poison (21). Finally, the general warning "keep all medicines out of reach of children", when modified to "out of reach and sight of children", proved to be effective in keeping their curiosity suppressed (19).

Although prevention is important, the post-incident arm cannot be ignored. PCCs need to be established to triage poisonings, dispense accurate and timely advice to caregivers and health facilities, direct first aid where appropriate, and refer the more severe cases to health facilities (1). Not surprisingly, thus, the regional poison center was found to significantly reduce pediatric visits to emergency rooms $(18,23,24)$; it also reduced parental anxiety and possible financial pressure.

Cultural barriers and low socioeconomic states result in these populations being unaware of the usefulness of PCCs or the inability to access them. Nevertheless, more than $50 \%$ of parents preferred to use the local poison center in case of an emergency (25). It is also interesting to note that PCC callers reported a higher prevalence of knowledge regarding prevention than did non-callers. This underscores the need for educational interventions to be directed at those who refuse to use these centers. 


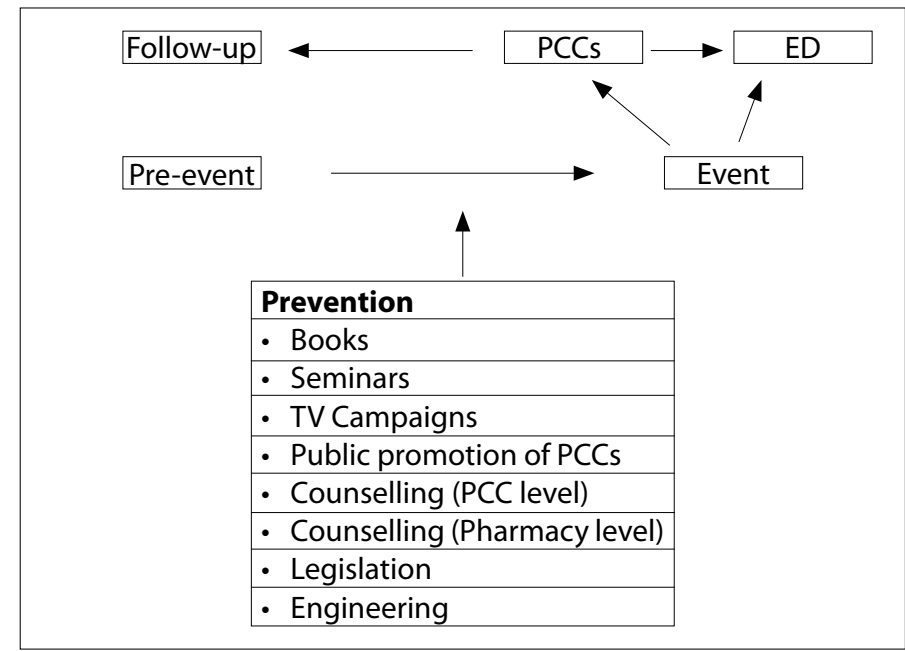

Figure 1. Management Strategies for APP in LMICs: In this model, the management of the problem is indicated through a stratified approach (pre-event vs. event/post-event)

APP: accidental pediatric poisoning; ED: emergency department; PCC: poison control centers; LMIC: low-and middle-income countries

To sustainably reduce the numbers of unintentional poison injuries, we thus make the case for developing preventative programs through awareness, advocacy, and opportunistic counseling. We further chose to suggest a model (Figure 1) for incorporating the PCCs at the pre-event (primary prevention), event (secondary prevention), and post-event (tertiary prevention) phases to help reduce the burden of EDs (24).

As Figure 1 suggests, with real advocacy, public and private healthcare-related partnerships (the collaboration of PCCs and ED units included), as well as national policy making, the APP incidence can be kept under control (25). However, making interventions in the pursuit of prevention and treatment is not enough - it is just as important to follow up on their progress and complete the feedback loop. Illustrated storybooks, aimed at reaching out to parents from all socioeconomic backgrounds, can effectively be put to use to increase awareness. Once the material is published in Urdu and locally distributed, it can be translated into other languages, such as Hindi for India and Swahili for Africa, and thus the model can be replicated in other LMICs. Television campaigns in the form of paid advertisements can also be generated to further the cause.

A limitation of this paper is in the inability to determine whether the model suggested will be reproducible in all LMICs, as it has not been tried and tested before. Nevertheless, this is one of the first reviews of its kind that focuses on APP in children aged $\leq 5$ years, presenting to the EDs of LMICs. Finally, since research on APP in Pakistan is majorly confined to only two or three hospitals, it will be important to further the existing data by surveying other hospitals, both in Karachi and Pakistan.

Peer-review: Externally peer-reviewed.

Conflict of Interest: No conflict of interest was declared by the authors.

Financial Disclosure: The authors declared that this study has received no financial support.

\section{References}

1. Children and Poisoning-Fact Sheet - World Health Organization. [online] 2016. Accessed November 25th, 2016. Available from URL: http://www. who.int/violence_injury_prevention/child/injury/world_report/Poisoning_english.pdf

2. Parikh CK. Clinical and Forensic Toxicology: In Parikh's Textbook of Medical Jurisprudence, Forensic Medicine and Toxicology 8th ed. New Delhi: CBS Publishers \& Distributors; 2006.p.110.77 .

3. London L, Baillie R. Challenges for improving surveillance for pesticide poisoning: policy implications for developing countries. Int J Epidemiol 2001; 30: 64-70. [CrossRef]

4. Osterhaudt KC, Shannon M, Henretig FM. Toxicological emergencies. In: Fleisher GR, Ludwig S. Textbook of Pediatric emergency medicine. 4th ed. Philadelphia: Lippincott Williams and Wilkins; 2000.p.887-97.

5. Hamid MH, Butt T, Baloch GR, Maqbool S. Acute poisoning in children. J Coll Physicians Surg Pak 2005; 15: 805-8.

6. Hyder AA, Sugerman DE, Puvanachandra P, Razzak J, El-Sayed H, Isaza A, et al. Global childhood unintentional injury surveillance in four cities in developing countries: a pilot study. Bull World Health Organ 2009; 87: 345-52. [CrossRef]

7. McKenzie LB, Ahir N, Stolz U, Nelson NG. Household cleaning product-related injuries treated in US emergency departments in 1990-2006. Pediatrics 2010; 126: 509-16. [CrossRef]

8. Schmertmann M, Williamson A, Black D, Wilson L. Risk factors for unintentional poisoning in children aged $1-3$ years in NSW Australia: a casecontrol study. BMC Pediatr 2013; 13: 88. [CrossRef]

9. Chatsantiprapa K, Chokkanapatik J, Pinpradit N. Host and environmental factors for exposure to poisons: A cross sectional study of preschool children in Thailand. Inj Prev 2001; 7: 214-17. [CrossRef]

10. Hon KL, Ho JK, Leung TH, Wong Y, Nelson EA, Fok TF. Review of children hospitalized for ingestion and poisoning at tertiary centre. Ann Acad Med Singapore 2005; 34: 356-61.

11. Ali MA, Kichi QK, Sharif N. Acute poisoning in children reported at B.V.Q / Quaid-i-Azam Medical College, Bahawalpur. Pak Ped J 2000; 24: 65-7

12. Aslam M, Baloch GR, Hussain W. Accidental poisoning in children. Pak Paed J 2002; 26: 67-70.

13. Babar MI, Bhait RA, Cheema ME, Kerosene oil poisoning in children. J Coll Physicians Surg Pak 2002; 12: 472-6.

14. Kendrick D, Smith S, Sutton A, Watson M, Coupland C, Mulvaney $C$ et al. Effect of education and safety equipment on poisoning-prevention practices and poisoning: systematic review, meta-analysis and meta-regression. Arch Dis Child 2008; 93: 599-608. [CrossRef]

15. Patel B, Groom L, Prasad V, Kendrick D. Parental poison prevention practices and their relationship with perceived toxicity: cross-sectional study. Inj Prev 2008; 14: 389-95. [CrossRef]

16. Ahmed B, Fatmi Z, Siddiqui AR. Population Attributable Risk of Unintentional Childhood Poisoning in Karachi Pakistan. Bhutta ZA, ed. PLoS One 2011; 6: e26881.

17. Gupta SK, Peshin SS, Srivastava A., Kaleekal T. A study of childhood poisoning at national poisons information centre, All India Institute of Medical Sciences, New Delhi. J Occup Health 2003; 45: 191-6. [CrossRef]

18. Manzar N, Saad SM, Manzar B, Fatima S. The study of etiological and demographic characteristics of acute household accidental poisoning in children-a consecutive case series study from Pakistan. BMC Pediatr 2010; 10: 28. [CrossRef]

19. Gibbs L, Waters E, Robinson J, Young S, Hutchinson A. Assessing the feasibility of distributing child poison safety messages through three existing parent information pathways. Inj Prev 2009; 15: 41820. [CrossRef] 
20. Ul Hassan O, Qadri H, Mir U, Ahmed B. Unintentional childhood poisoning, epidemiology and strategies for the prevention and policy change in Pakistan. J Ayub Med Coll Abbottabad 2013; 25: 90-3.

21. Krug A, Ellis JB, Hay IT, Mokgabudi NF, Robertson J. The impact of child-resistant containers on the incidence of paraffin (kerosene) ingestion in children. S Afr Med J 1994; 84: 730-4.

22. Fernando R, Fernando DN. Childhood poisoning in Sri Lanka. Indian J Pediatr 1997; 64: 457-60. [CrossRef]
23. Fernando R. The national poisons information centre in Sri Lanka: the first ten years. J Toxicol Clin Toxicol 2002; 40: 551-5. [CrossRef]

24. Lovejoy FH Jr, Robertson WO, Woolf AD. Poison centers, poison prevention, and the pediatrician. Pediatrics 1994; 94: 220-4.

25. Kelly NR, Kirkland RT, Holmes SE, Ellis MD, Delclos G, Kozinetz CA. Assessing parental utilization of the poison center: an emergency center-based survey. Clin Pediatr (Phila) 1997; 36: 467-73. [CrossRef] 